\title{
Post-Publication Discussion: Invitation for Reply
}

\author{
Mark S. Roh, MD' ${ }^{1}$, Douglas S. Tyler, $\mathrm{MD}^{2}$ on behalf of the Annals of Surgical Oncology Editors \\ ${ }^{1}$ Annals of Surgical Oncology, Orlando, FL; ${ }^{2}$ Department of Surgery, The University of Texas Medical Branch, Galveston, \\ TX
}

\section{FROM THE EDITORS}

In response to post-publication additional statistical analysis of their article 'Evaluation of a Gene Expression Profiling Assay in Primary Cutaneous Melanoma', ${ }^{1}$ Kangas-Dick et al. are invited to comment on issues raised in the following queries regarding potential selection bias and inadequate statistical reporting in the reported analysis. The authors are thanked in advance for participating in this post-publication discussion given the potential of an alternative interpretation of their published data.

1. It appears that an additional 40 patients with melanoma are present who had gene expression profiling (GEP) performed during the study period, which would bring the total melanoma pool of patients up from 361 to 401. Can the authors describe the exclusion/inclusion criteria for these patients and why were they excluded? Does adding them into the analysis change any of the conclusions?

2. How were patients from the 2013-2015 (retrospective) timeframe selected for GEP testing? How did the authors address potential selection bias? What were the characteristics of the patients who did not get tested? Had any of them already developed metastasis?

3. What is the impact of combining retrospective and prospective patients on the authors' conclusions? What are the results of GEP testing between the retrospective and prospective groups?

(C) Society of Surgical Oncology 2021

First Received: 20 September 2021

Accepted: 25 September 2021;

Published Online: 1 December 2021

M. S. Roh, MD

e-mail: editor@asoeditorial.org
4. It appears that only $75.9 \%$ of the 361 patients underwent sentinel lymph node biopsy (SLNB). Why did 87 patients forgo SLNB but still get GEP testing? What was the GEP class score for patients who did not undergo SLNB?

5. Please address inconsistencies in the results between the text, tables, and discussion. Provide more detail regarding the statistical methods and list the non-significant hazard ratios, confidence intervals, and $p$ values. This tends to center especially around the data presented in Tables 5 and 6 . Why were significant variables in univariate analysis not reported in multivariate analysis?

6. Provide the number of cases and events in the univariate and multivariate analyses.

The Author's reply and the invited companion editorial ${ }^{2}$ add important additional insight into the ongoing application of advances of surgical oncology research in the medical literature.

The Editors

Annals of Surgical Oncology

DISCLOSURES DST participated in a Castle Bioscience Advisory Board, and received royalty support from Up to Date. MSR reports nothing to disclose.

\section{REFERENCES}

1. Kangas-Dick AW, Greenbaum A, Gall V, et al. Evaluation of a Gene Expression Profiling Assay in Primary Cutaneous Melanoma. Ann Surg Oncol. 2021;28(8):4582-4589.

2. Sabel MS. Genomic expression profiling in melanoma and the road to clinical practice. Ann Surg Oncol. 2021. doi: https://doi.org/10. 1245/s10434-021-11099-3

Publisher's Note Springer Nature remains neutral with regard to jurisdictional claims in published maps and institutional affiliations. 